\title{
CONF-941011--6
}

\section{AGING MANAGEMENT OF CONTAINMENT STRUCTURES IN NUCLEAR POWER PLANTS}

\author{
Prepared For
}

\section{The Third International Conference on Containment Design and Operation}

Sponsored By

The Canadian Nuclear Society

The Toronto Hilton Hotel

Toronto. Canada

October 19-21, 1994

\section{By}

D. J. Naus and C. B. Oland (ORNL)

B. R. Ellingwood (JHU)

H. L. Graves. III and W. E. Norris (USNRC)

Oak Ridge National Laboratory (ORNL)

Oak Ridge. Tennessee 37831-8056

The Johns Hopkins University (JHU)

Baltimore. Maryland 21218-2686

U.S. Nuclear Regulatory Commission (USNRC)

Washington. D.C. 20555-0001

Research sponsored by the Office of Nucicar Reguiatory Research. L.S. Nuclear Regulatory Commission under interagency Agreement 1886-8084-5B with the L.S. Deparment or Energy under Contract DE-AC05-84OR21400. Accordingly, the L.S. Govemment retains a nonexclusive. royalty-iree license to pubish or reprousuce the published form of this contribution, or allow others to do io, ior L.S. Govemment purposes.

The submitted manuscript has been authored bv a contractor of the L.S. Government under Contract No. DE-ACO584OR2 1 t00. Accordingly, the L.S. Guvernment retains a nonexciustve, rovality-Iree license to publish or reproduce the pudished form of this contnoutuon, or allow ohers to do so. for L.S. Guvemment purposes. 


\section{DISCLAIMER}

Portions of this document may be illegible in electronic image products. Images are produced from the best available original document. 


\title{
AGING MANAGEMENT OF CONTAINMENT STRUCTURES IN NUCLEAR POWER PLANTS
}

\author{
D. J. Naus and C. B. Oland (ORNL) \\ B. R. Ellingwood (JHU) \\ H. L. Graves, III and W. E. Norris (USNRC)
}

\begin{abstract}
Research is being conducted by Oak Ridge National Laboratory under U.S. Nuclear Regulatory Commission (USNRC) sponsorship to address aging management of nuclear power plant containment and other safety-related structures. Documentation is being prepared to provide the USNRC with potential structural safety issues and acceptance criteria for use in continued service evaluations of nuclear power plants. Accomplishments include development of a Structural Materials Information Center containing data and information on the time variation of 144 material properties under the influence of pertinent environmental stressors or aging factors, evaluation of models for potential concrete containment degradation factors, development of a procedure to identify critical structures and degradation factors important to aging management, evaluations of nondestructive evaluation techniques. assessments of European and North American repair practices for concrete, review of parameters affecting corrosion of metals embedded in concrete, and development of methodologies for making current condition assessments and service life predictions of new or existing reinforced concrete structures in nuclear power plants.
\end{abstract}

Oak Ridge National Laboratory (ORNL)

Oak Ridge. Tennessee 37831-8056

The Johns Hopkins University ( $\mathrm{JHU}$ )

Baltimore. Maryland 21218-2686

U.S. Nuclear Regulatory Commission (USNRC)

Washington. D.C. 20555-0001

\section{DISCLAIMER}

This report was prepared as an account of work sponsored by an agency of the United States Government. Neither the United States Government nor any agency thereof, nor any of their employees, makes any warranty, express or implied, or assumes any legal liability or responsibility for the accuracy, completeness, or usefulness of any information, apparatus, product, or process disclosed, or represents that its use would not infringe privately owned rights. Reference herein to any specific commercial product, process, or service by trade name, trademark, manufacturer, or otherwise does not necessarily constitute or imply its endorsement, recommendation, or favoring by the United States Government or any agency thereof. The views and opinions of authors expressed herein do not necessarily state or reflect those of the United States Government or any agency thereof. 


\title{
AGING MANAGEMENT OF CONTAINMENT STRUCTURES IN NUCLEAR POWER PLANTS
}

\author{
D. J. Naus and C. B. Oland (ORNL) \\ B. R. Ellingwood (JHU) \\ H. L. Graves, III and W. E. Norris (USNRC)
}

\subsection{INTRODUCTION}

By the end of this decade, 63 of the 111 commercial nuclear power plants in the United States will be more than 20 years old, with some nearing the end of their 40-year operating license. Faced with the prospect of having to replace the lost generating capacity from other sources and the potential for substantial shutdown and decommissioning costs, many utilities are expected to seek extensions to their plant operating licenses. A major concern in evaluating such applications is ensuring that the capacity of the safety-reiated systems to mitigate extreme events has not deteriorated unacceptably due to either aging or environmental stressor effects during their previous service history. Although major mechanical and electrical equipment items in a plant could be replaced, if necessary, replacement of the containment and many other safety-related structural systems and components would be economically unfeasible. Approval for service life extension must be supported by evidence that these structures will continue to be capable of withstanding potential future extreme events.

\subsection{CONTAINMENT PERFORMAICE HISTORY}

In general, the performance of nuclear power plant containment structures has been very good. However, there have been several incidences where the capacity of the containment and other safety-related structures to meet future functional and performance requirements has been challenged. Degradation mechanisms that potentially can impact the performance of the safetyrelated reinforced concrete structures and containments include corrosion of the steel reinforcing systems, chemical attack, alkali-aggregate reactions. sulfate attack, frost attack, leaching, salt crystallization. and microbiological attack. Potential degradation mechanisms for steel containments and liners of the reinforced concrete containments are primarily related to corrosion and fatigue, with corrosion being the most limiting. Some of the aging concerns identified to date relative to structural integrity include inaccessibility of the reinforced concrete basemat for inspection to detect potential deterioration resulting from mechanisms such as leaching or sulfate attack: corrosion of steel reinforcement contained in water-intake structures; corrosion of embedded portion of the pressure boundary due to a breakdown of the seal at the concrete floor-to-shell or floor-to-liner intertace: corrosion of steel containment inaccessible exterior surface where water may accumulate in the sand pocket or be retained in regions where the non-structural material used to form the gap between the metal shell and concrete shield wall was left in place; corrosion of suppression pool interior surface just below the waterline due to a lack of, or degradation of, the protective coating: microbiologically-induced corrosion in locations such as the suppression pool and sand pocket adjacent to the drywell if the sand remains moist: regions where liner plate may be exposed to borated water. sodium pentaborate. or decontamination fluids; and fatigue and stresscorrosion cracking of stainless steel bellows.

\subsection{Reinforced Concrete Structures Experience}

The reinforced concrete structures are important to the overall safety of nuclear power plants in that they provide foundation. containment. support and shielding functions. Instances related to degradation of these structures primarily cccurred early in their life and have been corrected. 
Causes were primarily related to either improper material selection, construction/design deficiencies, or environmental effects. Examples of some of the more serious instances include voids under vertical tendon bearing plates resulting from improper concrete placement (Calvert Cliffs); cracking of post-tensioning tendon anchor heads due to stress corrosion or embrittlement (Bellefonte, Byron, and Farley); containment dome delaminations due to low quality coarse aggregate material and absence of radial reinforcement (Crystal River) or unbalanced prestressing forces (Turkey Point 3); water intake structure reinforcing steel corrosion (San Onofre); leaching of tendon gallery concrete (Three Mile Island); and low prestressing forces (Ginna, Turkey Point 3, Zion, and Summer). Other concrete-related problems have included occurrence of excessive voids or honeycomb in the concrete, contaminated concrete, cold joints, cadweld (steel reinforcement connector) deficiencies, materials out of specification, higher than code-allowable concrete temperatures, misplaced steel reinforcement, post-tensioning system buttonhead deficiencies, water contaminated corrosion inhibitors, and leakage of corrosion inhibitors from tendon sheaths. ${ }^{(1-4)}$

\section{$2.2 \quad$ Steel Structures Experience}

The carbon steel materials utilized to fabricate the steel containments and liners of reinforced concrete containments are susceptible to corrosion. As the nuclear power plant containments age, degradation incidences are starting to occur. As part of a life extension study at Monticello, a portion of the drywell concrete floor was excavated to examine the floor-to-shell interface where a polysulfide seal provided waterproofing. A $50-\mathrm{mm}$ corrosion band resulting from failure of the seal was found. Shell thickness loss was minimal $(<0.8 \mathrm{~mm})$. Steel containment shell corrosion was found at Oyster Creek in the sand cushion region of the drywell. The shell thickness had been reduced from a nominal value of $28 \mathrm{~mm}$ to an average thickness of $21.5 \mathrm{~mm}$ with some local areas reduced to $19 \mathrm{~mm}$. Corrosion was artributed to the presence of water that had leaked through a defective rubber gasket in a mechanical joint between the refueling bellows cavity drain line and the caviry liner plate. After passing the gasket, the water flowed through the air gap, through the gapforming material that contained sulfides and chlorides. and into the sand cushion where it collected due to inoperable drains. Wall thinning was also discovered at Oyster Creek above the sand cushion where gap-forming material was suspected to remain and retain moisture against the uncoated containment steel surface. General corrosion of the uncoated torus steel plate below the waterline was observed at Nine Mile Point 1. Ultrasonic examination of the torus shell showed several areas where the thickness was at or near the minimum required value. Limited inspections at Fitzpatrick, Millstone 1. Pilgrim. and Oyster Creek found degradation of coatings on the torus shell that required cleaning and recoating. Fitzpatrick exhibited some pitting corrosion and Pilgrim experienced flaking of the coating that led to rust formation. Base metal corrosion to a depth of about $10 \%$ the steel shell thickness was discovered on the outside surface of the steel containment vessel at McGuire 2. The corrosion occurred adjacent to a concrete floor in the annular space between the steel shell and surrounding concrete shield building at a location where the steel shell coating had degraded. The corrosion was caused by condensed boric acid resulting from leakage of compression tittings for instrumentation lines. The situation was exacerbated because of insufficient floor grading to prevent condensate from pooling between floor drains, and lack of a seal between the floor and steel shell. Similar, but less severe corrosion incidences have occurred at McGuire 1, and Catawba 1 and 2. General coating failures and surface corrosion, with localized corrosion pits to $1-\mathrm{mm}$ depth, also were found at McGuire 1 . The corrosion occurred on the inside surface of the steel shell at the floor level between the upper and lower containment compartments in the vicinity of the ice condenser where a 50-mm floor gap was located. Cork material. used as an intertace between the floor and steel shell. contained moisture that most likely originated from the ice condenser, condensation, or a combination of the two. Several incidences of transgranular 
stress corrosion cracking (TGSCC) have resulted in bellows leaking. At Quad Cities 1 excessive containment leakage occurred during a Type A leak-rate test due to a leaking drywell ventilation bellows. Two core spray bellows also had to be replaced due to excessive leakage. Also, TGSCC resulted in core spray bellows replacement at Quad Cities 1 and 2, and a control rod drive return line bellows at Dresden 3.

\subsection{CONCRETE STRUCTURAL AGING AND STEEL CONTAINMENTS AND LINERS PROGRAMS}

Recent experiences summarized above indicate the possibility that degradation effects may reduce the margin that containments have to accommodate accidents beyond the design basis. There is a need for improved surveillance, inspection/testing, and maintenance to enhance the technical bases for assurances of continued safe operation of nuclear power plants. The Concrete Structural Aging and Inspection of Steel Containments and Liners Programs have the overall objectives of preparing documentation that will provide the USNRC license reviewers with: (1) identification and evaluation of the structural degradation processes: (2) issues to be addressed under nuclear power plant continued-service reviews, as weil as criteria. and their bases, for resolution of these issues: (3) identification and evaluation of relevant in-service inspection or structural assessment programs: and (4) methodologies required to perform current condition assessments and reliabilitybased life predictions of the containment and other safety-related structures.

\subsection{Concrete Structural Aging Program}

The Structural Aging (SAG) Program was initiated in 1988 and is addressing aging management of safety-related concrete structures in nuclear power plants. Activities are being conducted under three major technical task areas - materials property data base. structural component assessment/repair technology, and quantitative methodology for continued service determinations.

\subsubsection{Materials Property Data Base}

The objective of the materials property data base task is to develop a reierence source that contains data and information on the time variation of material properties under the influence of pertinent environmental stressors or aging factors. The data base, in conjunction with service life models, has application in the prediction of potential long-term deterioration of critical structural components in nuclear power plants and in establishing limits on hostile environmental exposure for these structures. The results also have application to establishment of maintenance and remedial measures programs that will assist in either prolonging component service life or improving the probability of the component surviving an extreme event such as a loss-of-coolant accident. The data base has been developed in two formats - a handbook and an electronic data base. ${ }^{(\overline{)})}$

The Structural Materials Handbook is an expandable. four volume, hard-copy reference document containing complete sets of data and information for each material. Volume 1 contains performance and analysis iniormation (i.e.. mechanical. physical, and other properties) useful for structural assessments and safety margins evaluations. Volume 2 provides the data used to develop the periormance curves in Volume 1. Volume 3 contains material data sheets (e.g., constituent materials. generai information. and material composition). Volume 4 contains appendices describing the handbook organization and revision procedures. 
The Structural Materials Electronic Data Base is an electronicaily-accessible version of the handbook that provides an efficient means for searching the data base files. It has been developed on an IBM-compatible personal computer and employs two software programs - Mat.DB(6) and EnPlot (7). Mat.DB is a menu-driven software program for data base management that employs window overlays to access data searching and editing fearures. Textual, tabular, and graphical information and data can be maintained. searched, and displayed. EnPlot incorporates pop-up menus for creating and editing engineering graphs. It includes curve-fitting and scale-conversion features and has utility features for generating output files. Graphs generated can be entered directly into the Mat.DB data base files.

Two approaches have been utilized to obtain the data and information contained in the data base open-literature information sources and testing of prototypical samples. To date, 144 material data bases have been developed (i.e., 128 concrete, 12 metallic reinforcement, 1 prestressing steel, 2 structural steel, and 1 rubber). Examples of concrete material property data and information files currently available include compressive strength, modulus of elasticity and flexural strength versus time for several concrete materials cured under a variety of conditions (i.e., air drying, moist, or outdoor exposure) for periods up to 50 years; ultimate compressive strength and modulus of elasticity versus temperature at exposures up to $600^{\circ} \mathrm{C}$ for durations up to four months; weight loss versus time for specimens subjected to sulfuric acid concentrations (by weight) of 0.0016 to $0.02 \%$; length change versus time for specimens subjected to wet $\left(2.1 \% \mathrm{Na}_{2} \mathrm{SO}_{4}\right.$ solution) - dry cycling; bond stress versus slip for reinforced concrete bond test specimens exposed for 14 days to either direct or alternating current (potential up to 20 volts); and compressive strength versus time of concrete materials obtained from U.S. and United Kingdom nuclear power facilities. Metallic reinforcement (ASTM A 615 and A 15) pertormance curves are available for fatigue, and ambient and temperature-dependent (A 615 material only) engineering stress versus strain. Temperaturedependent engineering stress versus strain. and tensile yield strength, ultimate tensile strength, and ultimate elongation versus temperature periormance curves are available for both prestressing tendon (ASTM A 421, Type BA) and structural steel (ASTM A 36) materials. A temperaturedependent hardness versus time performance curve is available for a rubber material (ethylene propylene diene). A more detailed description of the data base and the files it contains is provided elsewhere. ${ }^{(8)}$

\subsubsection{Structural Component Assessment/Repair Technology}

The objectives of this task are to develop a systematic methodology that can be used to make quantitative assessments of the presence. magnitude. and significance of any environmental stressors or aging factors that can adversely impact the durability of safety-related concrete structures, and to provide recommended in-service inspection or sampling procedures that can be utilized to develop the data required to indicate the current condition and to trend the performance of these structures. Associated activities address repair of concrete components and corrosion of reinforced concrete structures.

A methodology has been developed that provides a logical basis for identifying the critical concrete structural elements in a nuclear power piant and the degradation factors that can potentially impact their performance. ${ }^{(9)}$ Numerical ranking systems were established to indicate the relative importance of a structure's subelements. the satery significance of each structure, and the potential influence of the particular environment to which it is exposed. Because of the variability in likelihood of occurrence of degradation in U.S. nuclear power plants due to differences in design, materials utilized in construction, geographical location, etc., the grading system for degradation factors was developed in terms of a range of possible values. The relative ranking of safety-related 
structures and their subelements is based on the weighted contributions of (1) the structural importance of subelements, (2) safety significance, (3) environmental exposure, and (4) significance of potential degradation factors. Results of this activity can be utilized as part of an aging management program to prioritize in-service inspection activities.

Direct and indirect techniques that can be used to detect degradation of concrete materials and structures have been reviewed. $(10)$ Capabilities, accuracies, and limitations of available nondestructive evaluation testing techniques were assessed (i.e., audio, electrical, impulse radar, infrared thermography, magnetic, stress wave reflection/refraction. modal analysis, radioactive/nuclear, rebound hammer, and ultrasonic). Information was also assembled on destructive (i.e., air permeability, break-off, chemical, coring, probe penetration, and pull-out) and emerging (i.e., leakage flux, nuclear magnetic resonance, capacitance-based, polarization resistance, ultraviolet radiation, and half-cell potential using impuise radar) techniques. Recommendations were provided on tesring methods to identify and assess damage resulting from typical factors that can degrade reinforced concrete. Correlation curves and statistical data were developed for selected nondestructive testing techniques. (11) This information is required where destructive and nondestructive tests cannot be conducted in tandem at noncritical locations to develop a regression relation between the two tests. Monovariant linear regression analyses were applied to data obtained from publications on five of the nondestructive testing techniques that are most commonly used to indicate concrete compressive strength (i.e., break-off, pull-out, rebound hammer, ultrasonic pulse velocity, and probe penetration). Data for each nondestructive technique were grouped by coarse aggregate type and aggregate mass function. The regression analyses accounted for the errors in both the nondestructive and compressive strength data and their constant coefficient of variation. The methods developed can be used for point estimates and estimates of the true mean. Variance of point estimates yields information about the distribution of the strength population which is required for calculating the characteristic strength needed to assess structural integrity.

Repair practices commonly used for reiniorced concrete structures in Europe and North America have been reviewed. $(12,13)$ Objectives of these reviews were to (1) describe repair materials and procedures commonly utilized. (2) establish criteria important to selection of a repair strategy, and (3) develop durability ratings for methods used to repair degradation that commonly occurs in reinforced concrete structures (e.g., dormant cracks. active cracks. spalls, and steel reinforcement corrosion). Steel reinforcement corrosion resulting from carbonation or presence of chlorides is the dominant type of distress that impacts reinforced concrete structures in Europe. Basic repair solutions include: (1) realkalization by either direct replacement of contaminated concrete with new concrete, use of a cementitious material overlay, or application of electrochemical means to accelerate diffusion of alkalis into carbonated concrete; (2) limining the corrosion rate by changing the environment (e.g., drying) to reduce the electrolvtic conductivity; (3) steel reinforcement coating (e.g., epoxy); (4) chloride extraction by passing an electric current (DC) from an anode attached to the concrete surface through the concrete to the reinforcement (chloride ions migrate to anode); and (5) cathodic protection. Properties of materials commonly used for repair (i.e., concrete, mortar, polymer-modified mortar. and epoxy mortar) were identified and relative durability ratings established for materiais used to seal concrete and repair cracks, spalls, and corroded steel. Repair strategies and procedures are provided in the form of flow diagrams. Tables have been prepared listing requirements for patch materials and coatings for reinforcement. Information specifically addressing inspection. degradation. and repair of reinforced concrete structures in light-water reactor plants was assembled through a questionnaire sent to U.S. utilities. Responses provided by 29 sites representing 41 units indicate that the majority of the plants perform inspections of concrete structures only in compliance with integrated-leak-rate test 
requirements (visual inspections), and surveillances of the post-tensioning systems of prestressed concrete containments. The 12 plants that do conduct regular inspections specifically addressing the concrete structures do so at intervals ranging from 1 to 5 years and rely mainly on visual techniques. Other methods have been utiized (e.g., pulse echo, pulse velocity, rebound hammer, and penerration resistance), but these appications were generally related to an assessment of degradation that had occurred. In generai, the performance of the concrete structures has been good with the primary forms of degradarion being concrete cracking and spalling, and steel reinforcement corrosion. The most common deterioration causes were drying shrinkage, acid/chemical attack, thermal movement, freeze-thaw cycles, and sea water exposure. The most common locations of deterioration for pressurized-water reactor plants were the containment dome and in the walls and slabs of the auxiliary structures. For the boiling-water reactor plants primary deterioration locations were in the walls. slabs, and equipment supports or pedestals of the reactor buildings and auxiliary structures. Most of the repair activities were associated with problems during initial construction (cracks, spalls. and delaminations), with the repairs performed on an asneeded basis. Little information was provided on materials used for repair, repair procedures, or the durability of repairs. When the periormance of a repair was evaluated, visual inspection was used.

A review of the corrosion of reinforced concrete structures, with an emphasis on stray electrical current-induced corrosion and use of cathodic protection to alleviate or mitigate corrosion in these structures has been completed. (14) Types of corrosion (uniform. pitting, bimetallic, crevice, etc.) that can occur on metals embedded in concrete were described as well as conditions that affect the corrosion rate (e.g., oxygen, electrolyte conductivity, ion concentration, temperature, etc.). Incidences involving corrosion of prestressing wires in concrete cooling water pipe and posttensioning tendon systems at nuclear power plants were listed. Methods available to detect corrosion occurrence include visual observations, half-cell potential measurements, delamination detection, electrolyte chemistry, corrosion monitors. acoustic emission, radiography, ultrasonics, magnetic perturbation, metallurgical properties, and electrical resistance. Remedial measures include damage repair. cathodic protection. inhibitors, chloride removal, membrane sealers, stray current shielding, dielectric isolation. coatings, and environmental modifications. Stray electrical current is any current flowing in a path other than its intended circuit and has a magnitude inversely proportional to the resistance of its path(s). Although stray electrical currents can result from a number of sources, those of most significance to the nuclear power industry include cathodic protection systems, high voltage direct current systems, and welding operations. Techniques to detect stray current include half-cell potential versus time study, half-cell potential versus distance study, and cooperative (interterence) testing. Mitigation measures for stray current include prevention or elimination of the current source. installation of cathodic protection, draining the çurrent from the source. and shielding the structure from the source. Cathodic protection is both a rehabilitation technique for corroding structures and a corrosion prevention technique for steel that may lose its inherent passivity at a later date. Cathodic protection mitigates the corrosion reaction by imposing current tlow between an anode and the metal to be protected. Impressed current systems use an external power source to force current flow between an anode on the concrete surface and the metal to be protected. Current is provided in sacrificial systems by connecting a metal that is more anodic (higher tendency to corrode) to the metal to be protected. The theory of cathodic protection is that galvanic corrosion of steel stops when the potential difference between the cathodic and anodic areas is zero. Design considerations. advantages and disadvantages, and commentary on when cathodic protection should and should not be used are discussed. Application of cathodic protection to high-strength steel used in prestressing wires or strands may result in embrittlement due to generacion of hydrogen at the cathode. 


\subsubsection{Quantitative Methodology for Continued Service Determinations}

The objective of this task is to develop a methodology to facilitate quantitative assessments of current and future structural reliability and performance of concrete structures in nuclear power plants. Methodologies have been developed for making condition assessments and service life predictions of new or existing reinforced concrete structures in nuclear power plants and hazardous waste depositories. $(15,16)$ These methodologies integrate information on design requirements, material and structural degradation, damage accumulation, environmental factors, and nondestructive evaluation (NDE) technology into a decision tool that provides a quantitative measure of structural reliability under projected future service conditions. This research has highlighted the need for quantitative modeling of strength degradation and the impact of NDE on in-service condition assessment.

\section{Time-Dependent Reliability Analysis}

Structural loads, engineering material properties. and strength degradation mechanisms are random in nature. Time-dependent reliability analysis methods provide a framework for performing condition assessments of existing structures and for determining whether in-service inspection and maintenance are required to maintain reliability and performance at the desired regulatory level.

The strength. $R(t)$, of the containment and the applied loads, $S(t)$, both are random (or stochastic) functions of time. At any time. $t$, the margin of safety, $M(t)$, is

$$
M(t)=R(t)-S(t) .
$$

Making the customary assumption that $R$ and $S$ are statistically independent random variables, the (instantaneous) probability of failure is.

$$
P_{f}(t)=P[M(t)<0]=\int_{0}^{\infty} F_{R}(x) f_{s}(x) d x .
$$

in which $F_{R}(x)$ and $f_{S}(x)$ are the probability distribution function of $R$ and density function of $S$. Equation 2 provides one quantitative measure of structural reliability and performance, provided that $\mathrm{P}_{\mathrm{f}}$ can be estimated and validated. The numerical evaluation of Eq. (2) and the development of supporting statistical data remain research challenges. However. significant progress has been made in this regard during the past several years.

For service life prediction and reliability assessment. one is more interested in the probability of satisfactory performance over some period of time. say $(0, t)$, than in the snapshot of the reliability of the structure at a particular time provided by Eu. (2). Indeed. it is difficult to use reliability analysis for engineering decision analysis withour having some time period (say, an in-service maintenance interval) in mind. The probability that a structure survives during interval of time $(0, \mathfrak{t})$ is cetined by a reliability function, $L(0 . t)$. If, for example, $n$ discrete loads $S_{1}, S_{2}, \ldots, S_{n}$ occur at times $t_{1}, t_{2}, \ldots, t_{n}$ during $(0, t)$, the reliability function becomes.

$$
L(0, t)=P\left[R\left(t_{1}\right)>S_{1}, \ldots . R\left(t_{n}\right)>S_{n}\right] .
$$

If the load process is continuous rather than discrete. there is an analogous but more complex expression. 
The conditional probability of failure within time interval $(t, t+d t)$, given that the component has survived during $(0, t)$, is defined by the hazard function:

$$
h(t)=-d \ln L(0, t) / d t .
$$

Solving for $\mathrm{L}(0, \mathrm{t})$ yields,

$$
L(0, t)=\exp \left[-\int_{0}^{t} h(x) d x\right] .
$$

The hazard function is especially useful in analyzing structural failures due to aging or deterioration. For example, the probability that time to structural failure, $T_{f}$, occurs prior to a future maintenance operation scheduled at $t+\Delta t$, given that the structure has survived to $t$, can be evaluated as,

$$
P\left[T_{f} \leq t+\Delta t \mid T_{f}>t\right)=1-\exp \left[-\int_{t}^{t+\Delta t} h(x) d x\right] .
$$

The hazard function for pure chance failures (case 1 in Fig. 1 below) is constant. When structural aging occurs and strength deteriorates, $h(t)$ characteristically increases with time. In-service inspection and maintenance impact the hazard function, causing it to change discontinuously at the time that in-service inspection is performed. The main difference between time-dependent reliability of undegrading and degrading structural components can be characterized by their hazard functions. Much of the challenge in structural reliability analysis involving deteriorating structures lies in relating the hazard function to specific degradation mechanisms, such as corrosion.

\section{Service Life Predictions}

Time-dependent reliability concepts are illustrated with a simple example of a concrete slab drawn from recent research on aging of concrete structures in nuclear plants. $(17,18)$ This slab was designed using the requirements for flexure strength found in ACI Standard 318(19):

$$
0.9 R_{n}=1.4 D_{n}+1.7 L_{n} \text {. }
$$

in which $R_{n}$ is the nominal or code resistance. and $D_{n}$ and $L_{n}$ are the code-specified dead and live loads, respectively. It is assumed that significant structural loads can be modeled as a sequence of load pulses, the occurrence of which is described by a Poisson process with mean rate of occurrence $\lambda$, random intensity $S_{j}$, and duration $\tau$. Such a simple load process has been shown to be an effective model for extreme loads on structures. since normal service loads challenge the structure to only a small fraction of its strength. At the same time, the strength of the slab changes in time, initially increasing as the concrete marures and then decreasing due to (unspecified) environmental attack. This situation is illustrated conceprually by the sample functions $r(t)$ and $s(t)$ for strength and load in Fig. 1. The behavior of the resistance over time must be obtained from mathematical models describing the degradation mechanism(s) present. 


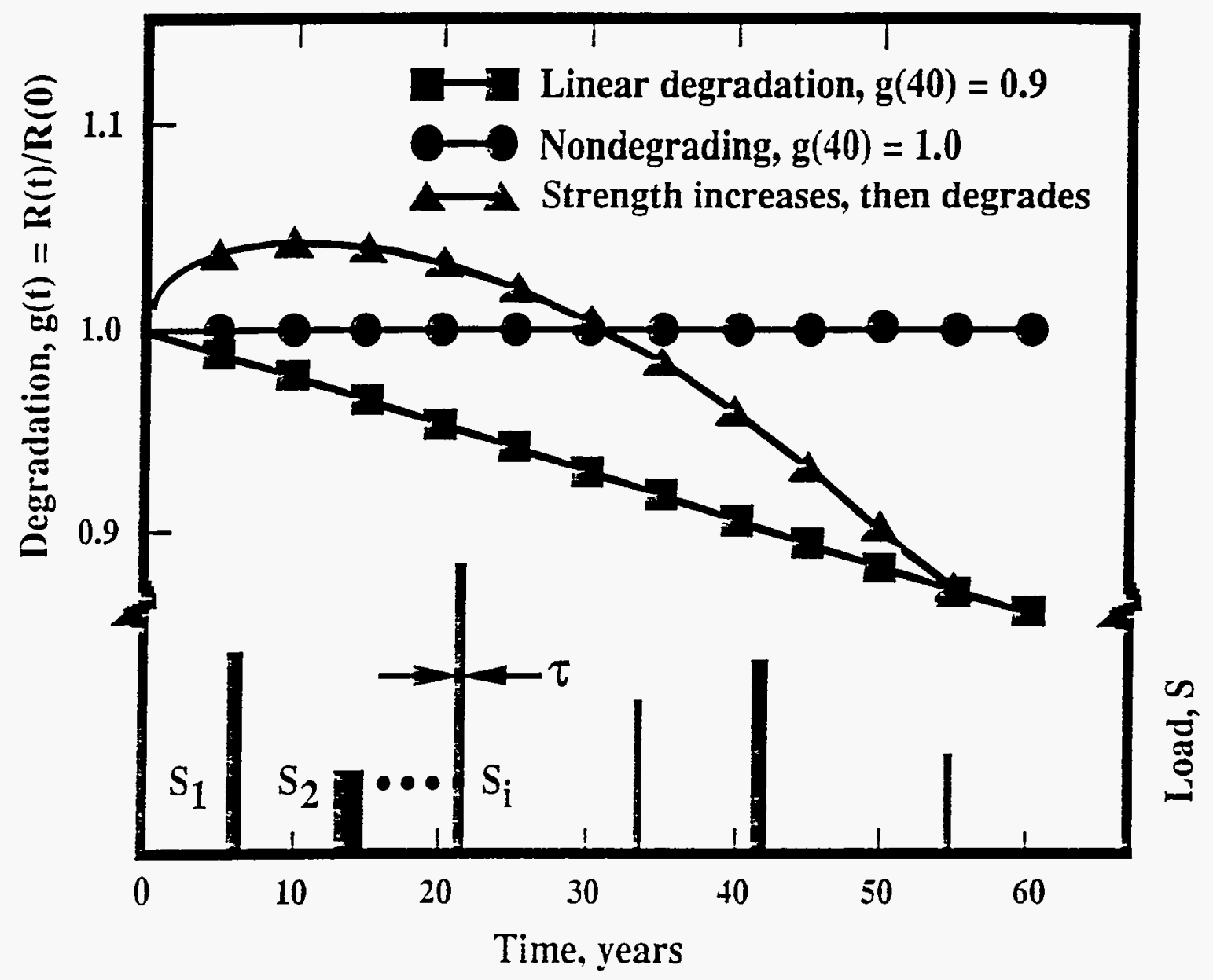

Fig. 1 . Mean degradation functions of one-way slab.

With the assumption that the load occurrence is a Poisson process. the reliability function becomes.

$$
L(0, t)=\int_{0}^{\infty} \exp \left(-\lambda t\left[1-t^{-1} \int_{0}^{t} F_{S}(r g) d t\right]\right) f_{R}(r) d r .
$$

in which $f_{R}(r)$ is the probability density function of initial strength, $R(0)$, and $g(t)$ equals $R(t) / R(0)$, a function describing the degradation of strength in time (see Fig. 1). The limit state probability, or probability of failure during $(0, t)$, can be determined as $F(t)=1-L(0, t)$. Note that $F(t)$ is not the same as $P_{f}(t)$ in Eq. (2).

Figure 2 presents a comparison of limit state probabilities for intervals $(0, t)$ for $t$ ranging up to 60 years. Three cases are presented (see Fig. 1): (1) no degradation in strength, i.e.. $R(t)=R(0)$, a random variable (this case is analogous to what has been done in probability-based code work to date:(20) (2) $R(t)$ initially increasing with concrete maturity and then degrading; and $(3) R(t)$ degrading linearly over time to $90 \%$ of its initial strength at 40 years. The basis for the statistics used in the illustrations that follow is given elsewhere. ${ }^{16)}$ Neglecting strength degradation entirely 
in a time-dependent reliability assessment can be quite unconservative, depending on the timedependent characteristics of strength.

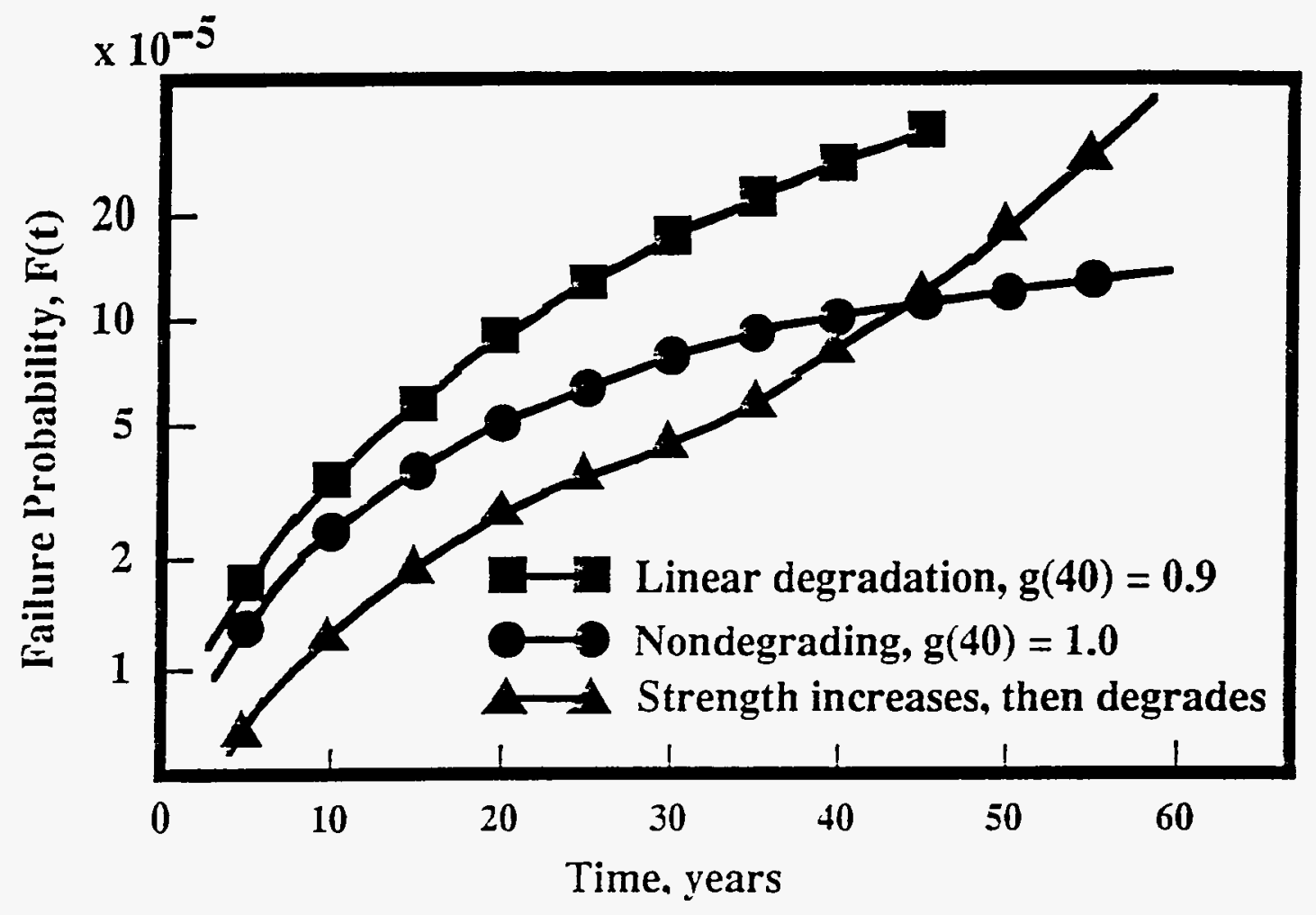

Fig. 2 Failure probability of a one-way slab.

\section{Condition Assessment and In-Service Inspection}

Forecasts of reliability of the type illustrated in Fig. 2 enable the analyst to determine the time period beyond which the desired reliability of the structure cannot be ensured. At such a time, the structure should be inspected. Intervals of inspection and maintenance that may be required as a condition for continued operation can be determined from the time-dependent reliability analysis. In-service inspection and maintenance are a routine part of managing aging and deterioration in many engineered facilities; work already has been initiated to develop policies for offshore platforms ${ }^{(21)}$ and aircraft $(22)$ using probabilistic methods.

When a structure is inspected and/or repaired. something is learned about its in-service condition that enables the probability distribution of strength to be updated. The density function of strength, based on prior knowledge of the materials in the structure, construction and standard methods of analysis, is indicated by $f_{R}(r)$. Scheduled inspection. maintenance and repair cause the characteristics of strength to change; this is illustrated by the (conditional) density $f_{R}(r \mid B)$, in which $B$ is an event dependent on in-service inspection. The information gained from inspection usually involves several structural variables. including dimensions. defects and perhaps an indirect measure of strength or stiffness. If these variables can be related through event $B$, then the updated density of $\mathrm{R}$ following in-service inspection is. 


$$
f_{R}(r \mid B)=P[r<R \leq r+d r, B] / P[B]=c K(r) f_{R}(r)
$$

in which $f_{R}(r)$ is termed the prior density of strength, $K(r)$ is denoted the likelihood function and $c$ is a normalizing constant. The time-dependent reliability analysis then is re-initialized following inservice inspection/repair using the updated $f_{R}(r \mid B)$ in place of $f_{R}(r)$. The updating causes the hazard function to be discontinuous.

Uncertainties in methods of in-service inspection/repair affect the density $f_{R}(r \mid B)$. Using a combination of methods usually is more effective from a reliability point of view than using one method. When there are limited resources, it often is most effective to select a few safety-critical elements and concentrate on them. $(9,16)$ Optimal intervals of inspection and repair for maintaining a desired level of reliability can be determined based on minimum life cycle expected cost considerations. Preliminary investigations of such policies have found that they are sensitive to relative costs of inspection, maintenance and failure. (18) If the cost of failure is an order (or more) of magnitude larger than inspection and maintenance costs, the optimal policy is to inspect at nearly uniform intervals of time. However, additional research is required before such policies can be finalized as part of an aging management plan.

\subsection{Steel Containments and Liners Ptogram}

The inspection of steel containments and liners of reinforced concrete containments program initiated in September 1993. It has the overall objective of understanding the significant factors relating occurrence of corrosion. efficacy of inspection, and structural capacity margins for steel containments and liners. Activities are being conducted under two technical task areas assessment and repair technologies, and reliability-based condition assessment.

\subsubsection{Assessment and Repair Technoiogies}

The overall objectives of this task are to (1) identify procedures to quantitatively assess the presence. magnitude. and significance or any degradation factors that can impact structural capacity margins: and (2) provide data for use in current or ruture structural condition assessments. In addition, techniques will be established for (1) characterization of steel containment, steel liner, coating, and seal materials; (2) mitigation of environmental stressor or aging factor effects; and (3) repair, replacement, or retrofitting of degraded components. Current activities involve development of a plan for presenting properties of containment pressure boundary materials and evaluation of destructive and nondestructive evaluation techniques and methodologies.

Characterization of containment pressure boundary materials is addressing the collection and presentation of data and information on these materials. and quantifying the affects (if any) of degradation factors such as corrosion on their properties. Desired data and information requirements for characterization of containment pressure boundary materiais have been developed (i.e., general information covering a description of the material. processing information, and baseline data: material composition in terms of chemistry; and mechanical, physical, and other properties). Structural steels acceptable for use in the construction of the containment pressure boundary have been identified along with their corresponding American Society of Mechanical Engineers (ASHLE) and American Society for Testing and Materials specifications (ASTM) (e.g., carbon steel. AS.ME SA-36, and ASTMI A 36). Potential nuclear power plant-related degradation factors for these materials have been identified - corrosion, fatigue. neutron irradiation, and extreme thermai exposure. Of these. corrosion is thought to be of most significance, followed by fatigue. Two options are under consideration for presentation of the materials property data and 
information - incorporate additional chapters into the existing Structural Materials Information Center, or use of object-oriented relational data base software to develop a customized data base. More detailed information on the characterization, assemblage and presentation of data and information on containment pressure boundary materials will be provided in a plan which is under development.

An essential element in the assessment of integrity (or in the determination of available structural capacity margins) of a containment structure is knowledge of the damage state of its material(s) of construction. Future condition assessments require not only knowledge of the current damage state, but knowledge of its change with time. In-service inspections are performed to measure the current state of damage. Changes in damage state with time can be indicated through physical models, correlation relations, or trending analyses. Many of the existing in-service inspection techniques have been developed primarily for the detection and assessment of fabrication-related flaws under controlled conditions. These techniques may not be adequate for use in helping to effectively manage the aging of the containment steel pressure boundary. In addition, accessibility of the steel-containment boundary may be restricted due to the presence of coatings, their location below water level, being embedded in concrete, or being accessible from only one surface. Because the steel-containment boundary plays a vital role in preventing the release of radioactive fission products in the unlikely event of an accident, the in-service inspection requirements on these structures in general require a higher level of reliability and more quantitative definition of defects present than those associated with the general manufacturing sector. In this regard, activities have been initiated to identify and evaluate techniques and methodologies that can be used to quantitatively assess the presence, magnitude, and significance of degradation factors, especially in suspect areas noted previously, that can impact structural capacity margins of the steel pressure boundary. The role of statistics in damage detectability is also being addressed.

\subsubsection{Reliability-Based Condition Assessment}

The overall objectives of this task are to (1) identify mathematical models from principles of structural mechanics to evaluate degradation in strength of steel structures over time, (2) recommend statistically-based sampling plans for inspection of steel structures to ensure that any damage present will be detected with a specified level of confidence, and (3) develop reliability-based methods to assess the probability that steel containment capacity has degraded below a specified level. This task will provide quantitative evidence that the strength of the steel pressure boundary is sufficient to withstand operating and environmental events with a level of reliability that is sufficient to protect public health and safety.

Structural aging may cause the integrity of the steel pressure boundary to evolve over time. Its strength and stiffness properties may degrade in hostile service environments from corrosion, fatigue or crack propagation, or material changes. An evaluation of the reliability of the pressure boundary during a period of continued service must include these past challenges on its integrity. The random fashion in which degradation occurs must be taken into account in development of risk management policies and procedures. Uncertainties that complicate the evalution of aging effects in structures arise from a number of sources: (1) inherent randomness in structural loads; (2) lack of in-service measurements and records; (3) limitations in available models for quantifying time-dependent material changes and their contribution to steel pressure boundary integrity; (4) inadequacies of nondestructive evaluation techniques; and (5) shortcomings in existing methods to account for repair. Activities are developing an approach for condition assessment and damage analysis to relate significant material aging factors and degradation and structural loads to engineering properties needed for a structural assessment. 
Predictive models are being identified that enable the change in strength of a steel structure with time to be evaluated in terms of initial conditions, applied load history, and a parameterization of an aggressive environment. These models are based on structural mechanics and theoretical relationships, and need to be calibrated to actual data. For some mechanisms of strength degradation (e.g., stable crack growth under cyclic load), the mechanics of deterioration are reasonably well established and predictable through fracture mechanics. (23-25) In other cases (e.g., thermal cycling and irradiation), the behavioral models are less certain requiring development from laboratory tests. These mechanisms, however, are considered to be of secondary importance relative to corrosion or fatigue. Structural aging and deterioration cause the conditional failure rate of a structure to increase with time. Data to describe the factors that can impact structural durability are being quantified (i.e., operating conditions, environmental stressors, design bases, material quality, and construction methods). Uncertainties associated with those data are being determined. Structural loads arising from service, extreme environmental or accidental conditions are being modeled as stochastic processes, $(26,27)$ as well as environmental conditions under which the structures operate.

The methodologies under development will quantify residual structural strength or predict future service life. They will integrate areas of damage mechanics, stochastic characterization of the plant environment, service load history, and current strength to determine probability distributions of structural safety margins at some future time. Probability distributions of additional usable life associated with a minimum structural capacity will be determined. The time-dependent reliability analysis can be used to determine intervals of inspection and maintenance. $(21,28,29)$ Incorporation of nondestructive information into a reliability-based structural condition assessment can have significant long-term economic and safety benefits. Statistically-based sampling plans will be developed to guide the extent of the structure to be inspected during each scheduled inspection/maintenance period. Finally, a cost-benefit analysis of alternate inspection/maintenance strategies incorporating estimates of structural performance and reliability can be used to develop rational in-service inspection/maintenance policies to support service life extension.

\subsection{APPLICATION OF RESULTS}

Potential regulatory applications of this research include: (1) improved predictions of long-term material and structural performance and available safery margins at future times: (2) establishment of limits on exposure to environmental stressors; (3) reduction in total reliance by licensing on inspection and surveillance through development of a methodology that will enable the integrity of structures to be assessed (either pre- or post-accident): and (4) improvements in damage inspection methodology through potential incorporation of results into national standards that could be referenced by standard review plans.

\subsection{REFERENCES}

1. D. J. Naus. Concrete Component Aging and Its Significance Relative to Life Extension of Nuclear Power Plants, NUREG/CR-4652 (ORNL/TM-10059), Martin Marietta Energy Systems, Inc., Oak Ridge National Laboratory, Oak Ridge, Tennessee, September 1986.

2. H. Ashar. D. J. Naus. and C. P. Tan. "Prestressed Concrete in U.S. Nuclear Power Plants (Part 1)," pp. 30-34 in Concrete International. 16(5), American Concrete Institute, Detroit, Michigan, May 1994. 
3. H. Ashar, C. P. Tan, and D. J. Naus, "Prestressed Concrete in U.S. Nuclear Power Plants (Part 2)," pp. 58-61 in Concrete International, 16(6), American Concrete Institute, Detroit, Michigan, June 1994.

4. H. Ashar and D. Jeng, "Effectiveness of In-Service Inspection Requirements of Prestressed Concrete Containments - U.S. Experience," Proceedings of Second International Conference on Containment Design and Operation, Toronto, Ontario, Canada, October 1990.

5. C. B. Oland and D. J. Naus, Structural Materials Information Center for Presentation of the Time Variation of Materials Properties, ORNL/NRC/LTR-90/22, Martin Marietta Energy Systems, Inc., Oak Ridge National Laboratory, Oak Ridge, Tennessee, November 1990.

6. Mat.DB, Version 1.22, ASM International. ASM/Center for Materials Data, Materials Park, Ohio, 1992.

7. EnPlot, Version 3.5, ASM International. ASM/Center for Materials Data, Materials Park, Ohio, 1993.

8. C. B. Oland and D. J. Naus. Summary of Materials Contained in the Structural Materials Information Center, ORNL/NRC/LTR-94/22. Martin Marietta Energy Systems, Inc., Oak Ridge National Laboratory, Oak Ridge. Tennessee, July 1994 (Draft).

9. C. J. Hookham. Structural Aging Assessment Methodology for Concrete Structures in Nuclear Power Plants, ORNL/NRC/LTR-90/17 (Subcontract Report 11X-SD343V from Multiple Dynamics Corporation. Southfield, Michigan), Martin Marietta Energy Systems, Inc.. Oak Ridge National Laboratory, Oak Ridge, Tennessee. March 1991.

10. T. M. Refai and M. K. Lim. Inservice Inspection and Structural Integrity Assessment Methods for Nuclear Power Plant Concrete Structures, ORNL/NRC/LTR-90/29 (Subcontract Report 17X-SE611V from Construction Technology Laboratories, Inc., Skokie, Illinois), Martin Marietta Energy Systems, Inc., Oak Ridge National Laboratory, Oak Ridge. Tennessee. September 1991.

11. K. A. Snyder. J. R. Clifton, and N. J. Carino. Nondestructive Evaluation of the In-Place Compressive Strength of Concrete Based Upon Limited Destructive Testing, NISTIR 4874, National Institute of Standards and Technology, U.S. Department of Commerce, Gaithersburg, Maryland, July 1992.

12. W. F. Price. P. B. Bamforth. and G. K. Glass. Review of European Repair Practice for Corrosion Damaged Reinforced Concrete, Report No. 1303/91/5823 (Subcontract No. 31X-SH469V), Taywood Engineering Ltd.. London, England, April 1993.

13. P. D. Krauss. Repair Materiais and Techniques for Concrete Structures in Nuclear Power Plants. ORNL/NRC/LTR-93/28 (Subcontract 90X-SJ024C with Wiss, Janney, Elstner, and Associated. Inc.. Northbrook. Illinois), Martin Marietta Energy Systems, Inc., Oak Ridge National Laborator:. Oak Ridge, Tennessee. March 1994. 
14. W. J. Swiat, W. Young, J. Pajak, M. Funahashi, D. Burke, and J. Wagner, State-of-theArt Report - Corrosion of Steel in Concrete, ORNL/NRC/LTR-93/2 (Subcontract Report 1BX-SK529V from Corrpro Companies, Inc., Medina, Ohio), Martin Marietta Energy Systems, Inc., Oak Ridge National Laboratory, Oak Ridge, Tennessee, May 1993.

15. D. J. Naus, C. B. Oland, B. Ellingwood, Y. Mori, and E. G. Arndt, "An Overview of the ORNL/NRC Program to Address Aging of Concrete Structures in Nuclear Power Plants," pp. 327-339 in Nuclear Engineering and Design, 142, 1993.

16. B. Ellingwood and Y. Mori, "Probabilistic Methods for Condition Assessment and Life Prediction of Concrete Structures in Nuclear Plants," pp. 155-166 in Nuclear Engineering and Design, 142, 1993.

17. Y. Mori and B. Ellingwood, "Maintaining Reliability of Concrete Structures I: Role of Inspection/Repair," pp. 846-862 in Journal of Structural Engineering, 120(3), ASCE, 1994.

18. Y. Mori and B. Ellingwood, "Maintaining Reliability of Concrete Structures II: Optimal Inspection/Repair," pp. 846-862 in Journal of Structural Engineering, 120(3), ASCE, 1994.

19. "Building Code Requirements for Reinforced Concrete." ACI 318-89, Rev. 92, American Concrete Institute, Detroit, Michigan. 1989.

20. B. Ellingwood and T. V. Galambos. "Probability-Based Criteria for Structural Design," pp. 15-26 in Structural Safetr, 1(1), 1982.

21. H. Madsen. J. D. Sorensen, and R. Olesen, "Optimal Inspection Planning for Fatigue Damage of Offshore Structures." pp. 2099-2106 in Proceedings of ICOSSAR '89, Vol. III. Structural Safety and Reliability, ASCE, New York, 1989.

22. J. Yang, "Application of Reliability Methods to Fatigue. Quality Assurance, and Maintenance." pp. 3-18 in Proceedings of ICOSSAR '93. Vol. I, Structurai Safety and Reliability, A. A. Balkema, Rotterdam, The Netheriands, 1994.

23. "Prediction of Service Life of Building Materiais and Components," pp. 55-77 in Materials and Structures, 20, CIB W80/RILEM 71-SPL. 1987.

24. Oswald and G. Schueller, "Reliability of Deteriorating Structures," pp. 479-488 in Engineering Fracture Mechanics. 20(3), 1984.

25. J. Nienstedt, A. Tsurui, H. Tanaka. and G. I. Schueiler, "Time-Variant Structural Reliability Analysis Using Bivariate Diffusive Crack Growth Models." pp. 83-89 in Int. Journal of Fatigue. 12(2), 1990.

26. B. Ellingwood and Y. Mori. Concition Assessment and Reliability-Based Life Prediction of Concrete Structures in Nuclear Plants, Report ORNL/NRC/LTR-92/4, Oak Ridge National Laboratory, Oak Ridge, Tennessee, 1992. 
27. T. H. Pearce and Y. K. Wen, "Stochastic Combinations of Load Effects," pp. 1613-1629 in Journal of Structural Engineers, 110(7), ASCE, 1985.

28. M. Fujita, G. Schall, and R. Rackwitz, "Adaptive Reliability-Based Inspection Strategies for Structure Subjected to Fatigue," pp. 1619-1626 in Structural Safety and Reliability (ICOSSAR '89), Vol. II, ASCE, New York, 1989.

29. H. O. Madsen, "Model Updating in Reliability Theory," pp. 564-577 in Reliability and Risk Analysis in Civil Engineering, (ICASP 5, 1987), University of Waterloo, 1987. 